\title{
1,2-Azaborolyl-Ligated Titanium(IV) Half-Metallocenes: Synthesis, Characterization and Catalytic Activity in Ethylene Polymerization
}

Yang Chen, Xiangdong Fang * and Wenyan Dan

Department of Chemistry, Shanghai Key Laboratory of Chemical Assessment and Sustainability (CAS), Tongji University, 1239 Siping Road, Yangpu District, Shanghai 210092, People's Republic of China.

\section{Content}

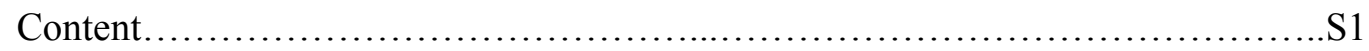

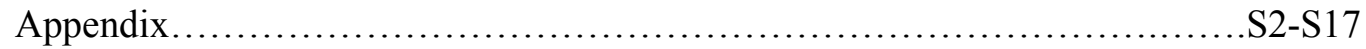

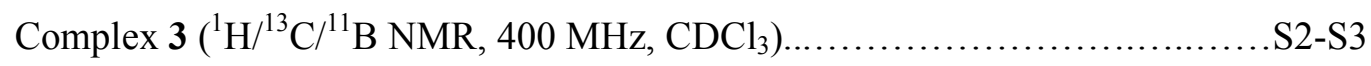

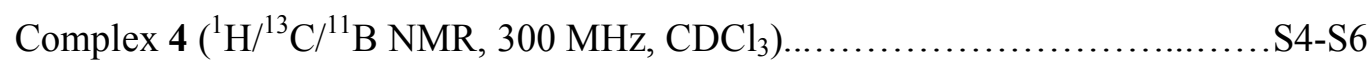

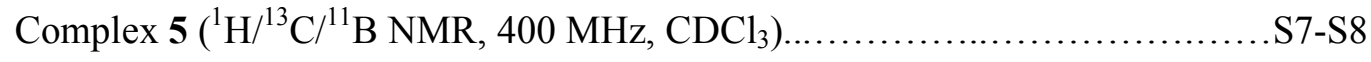

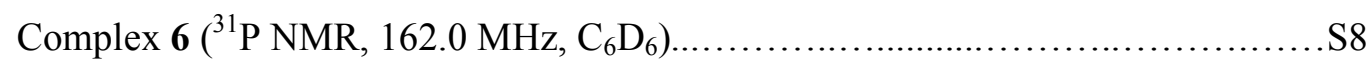

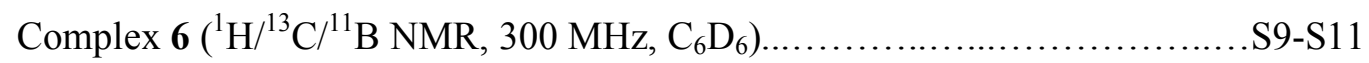

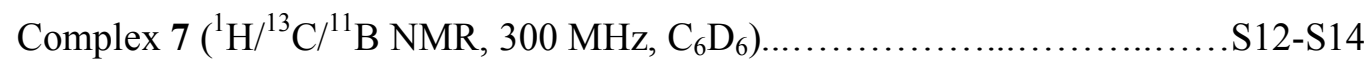

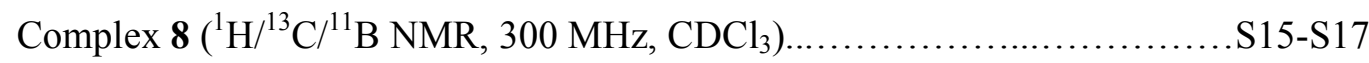


Appendix: $\quad{ }^{1} \mathrm{H} /{ }^{13} \mathrm{C} /{ }^{11} \mathrm{~B} /{ }^{31} \mathrm{P}$ NMR Spectra of Complexes 3-8

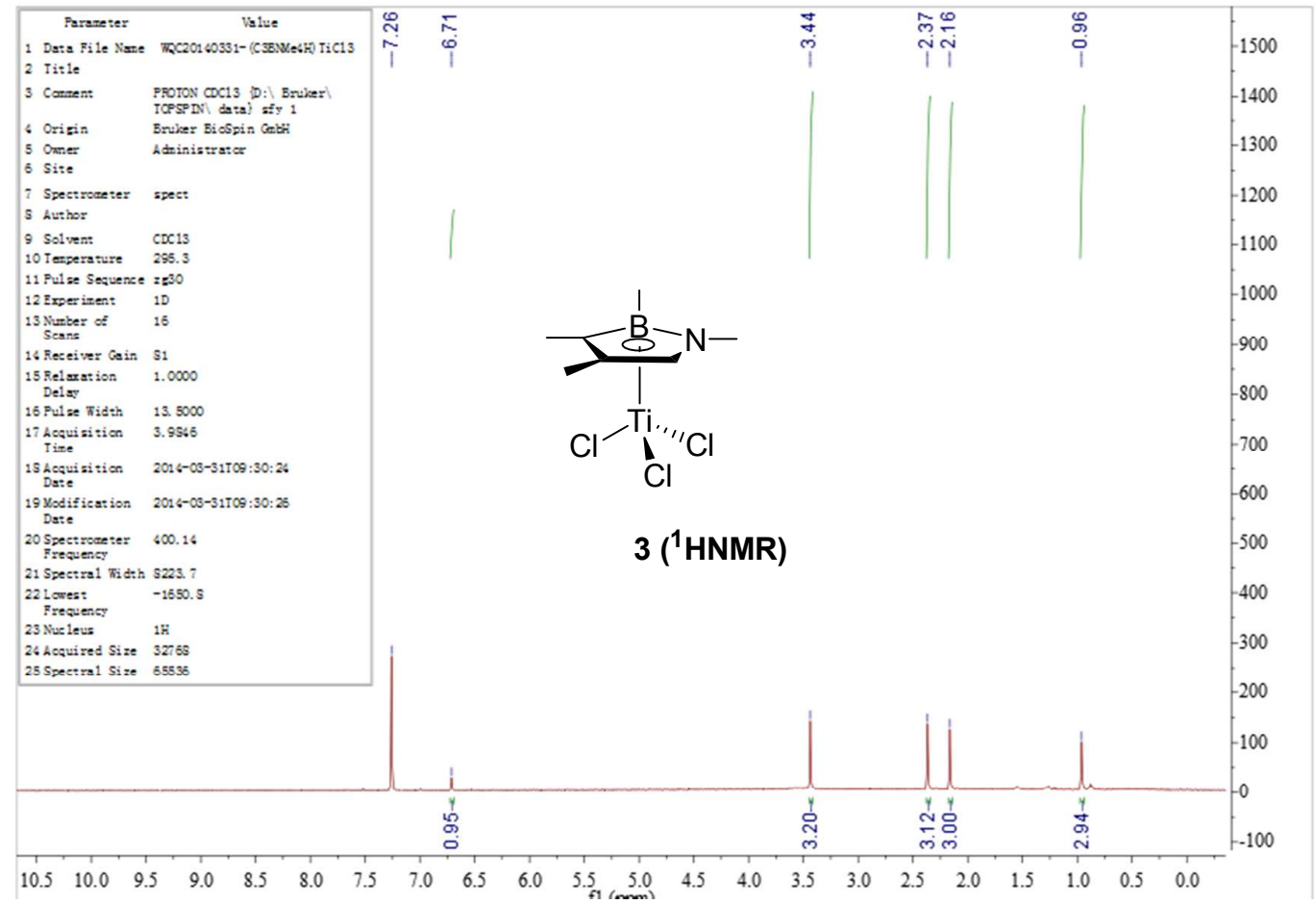



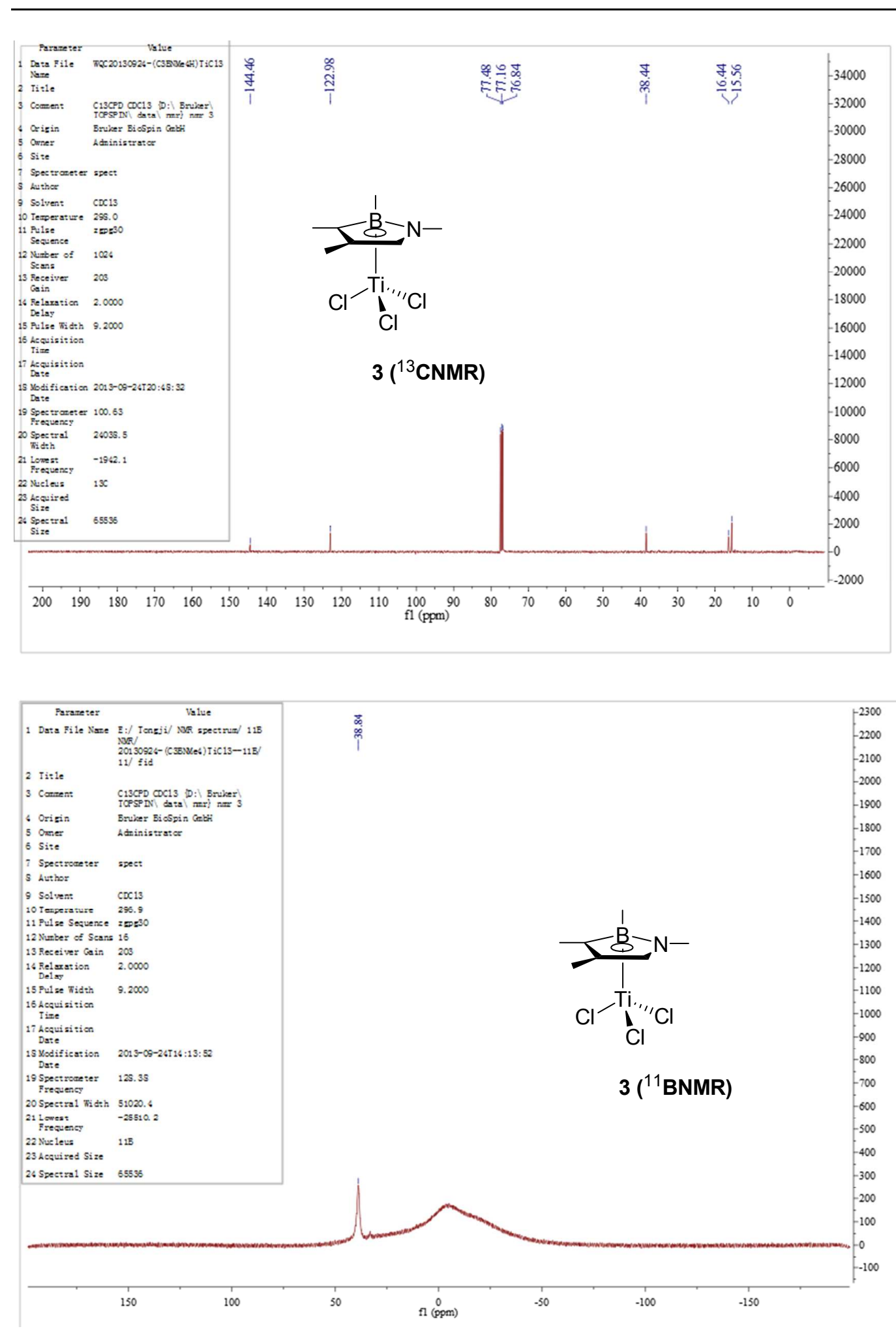


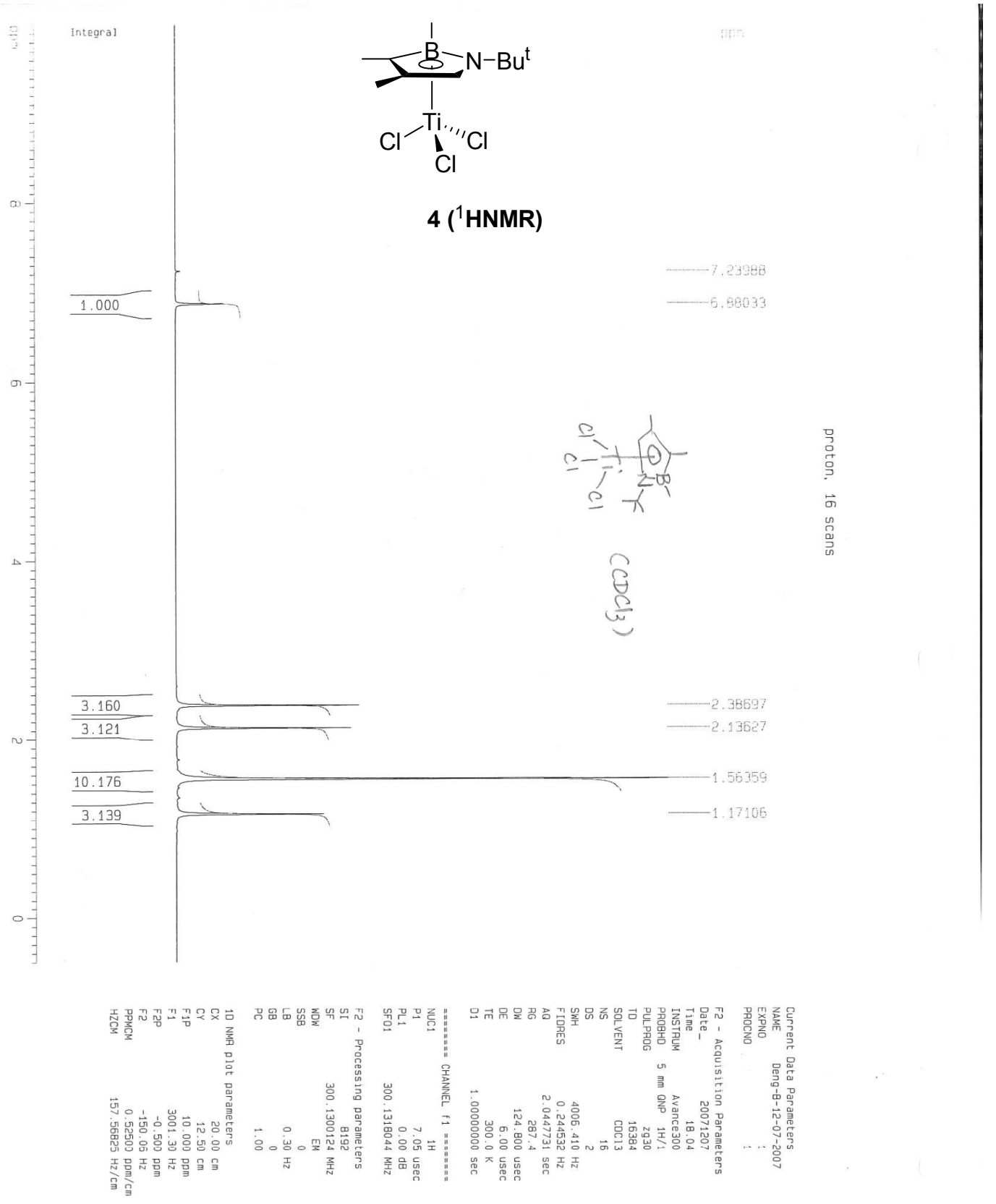




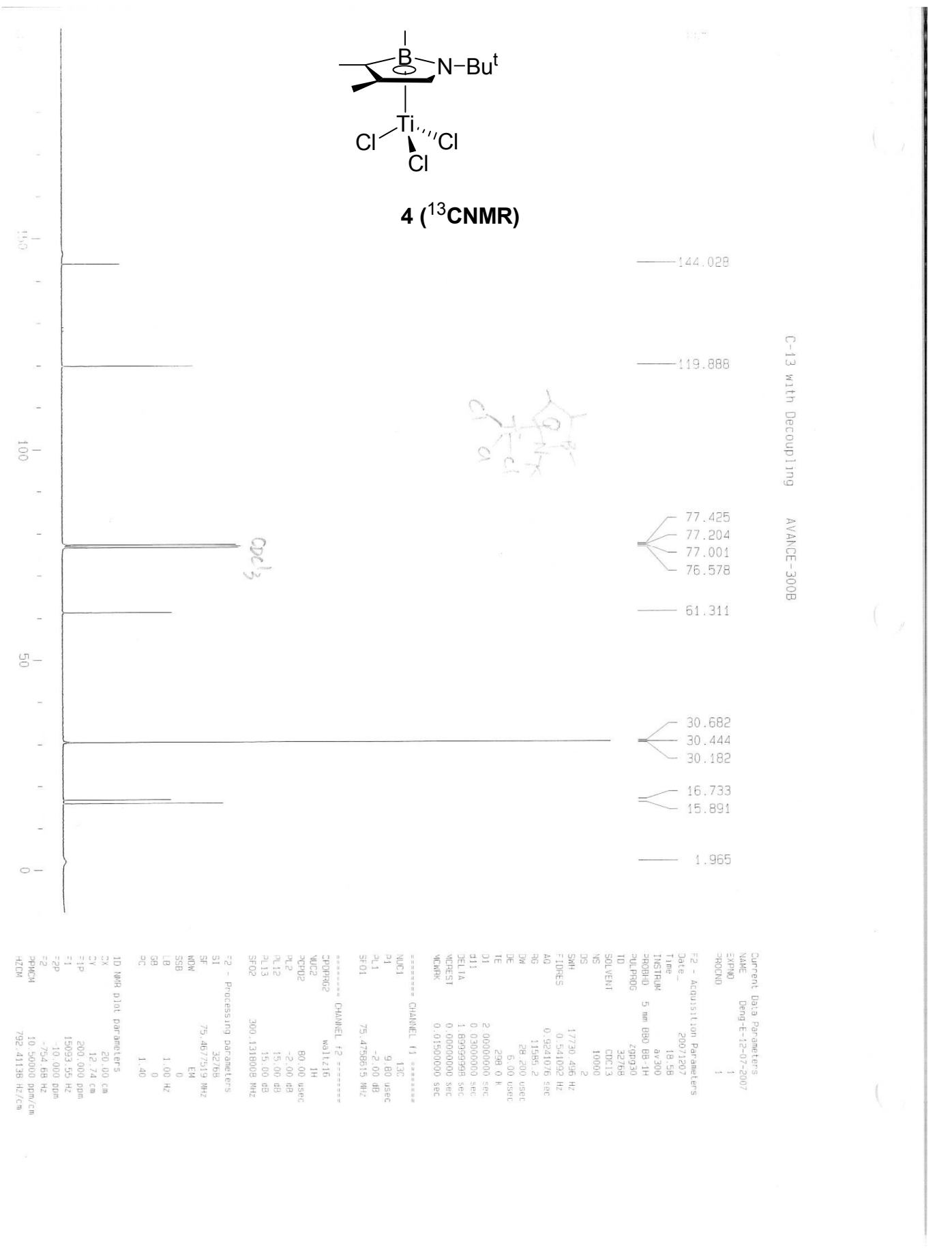




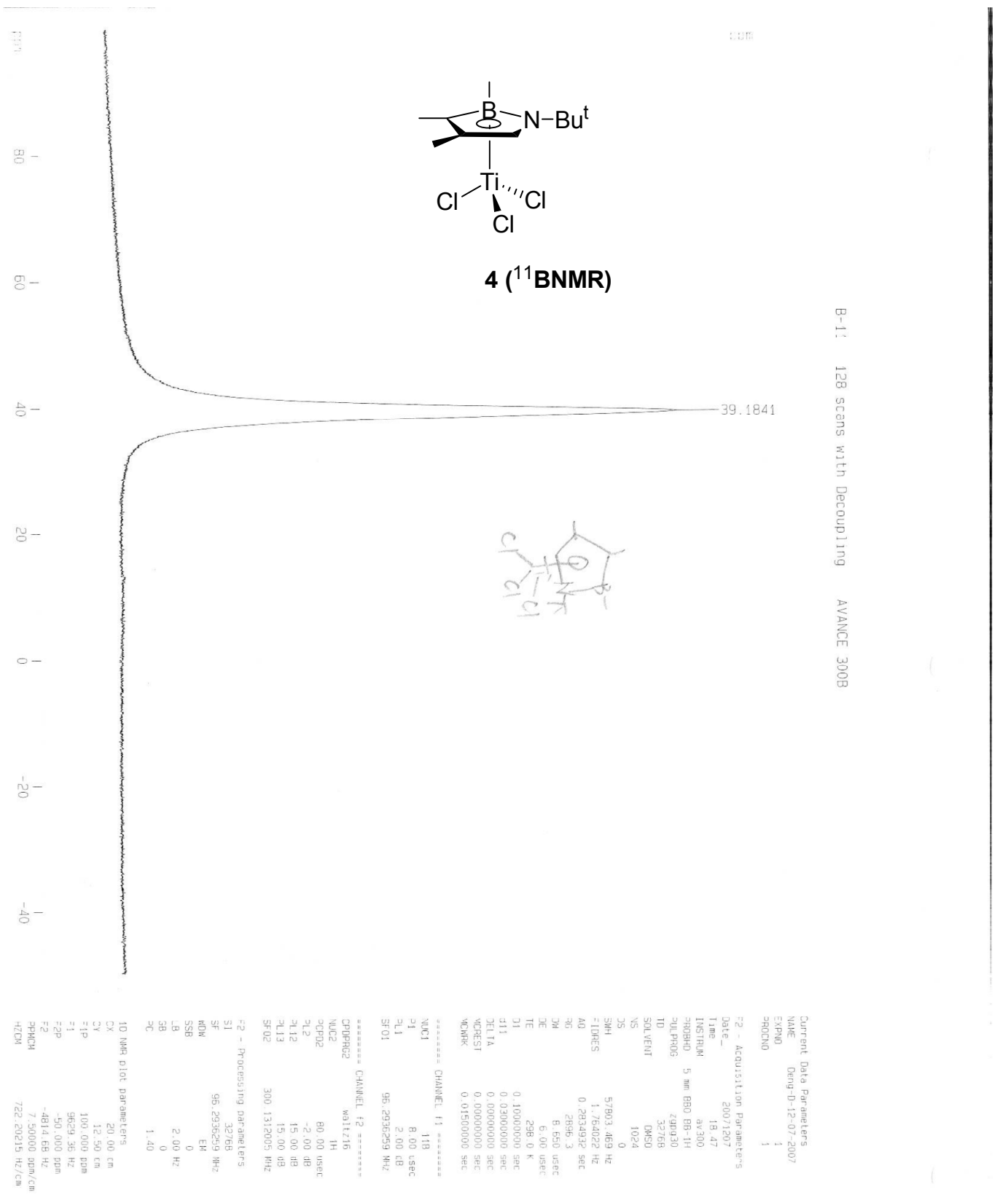



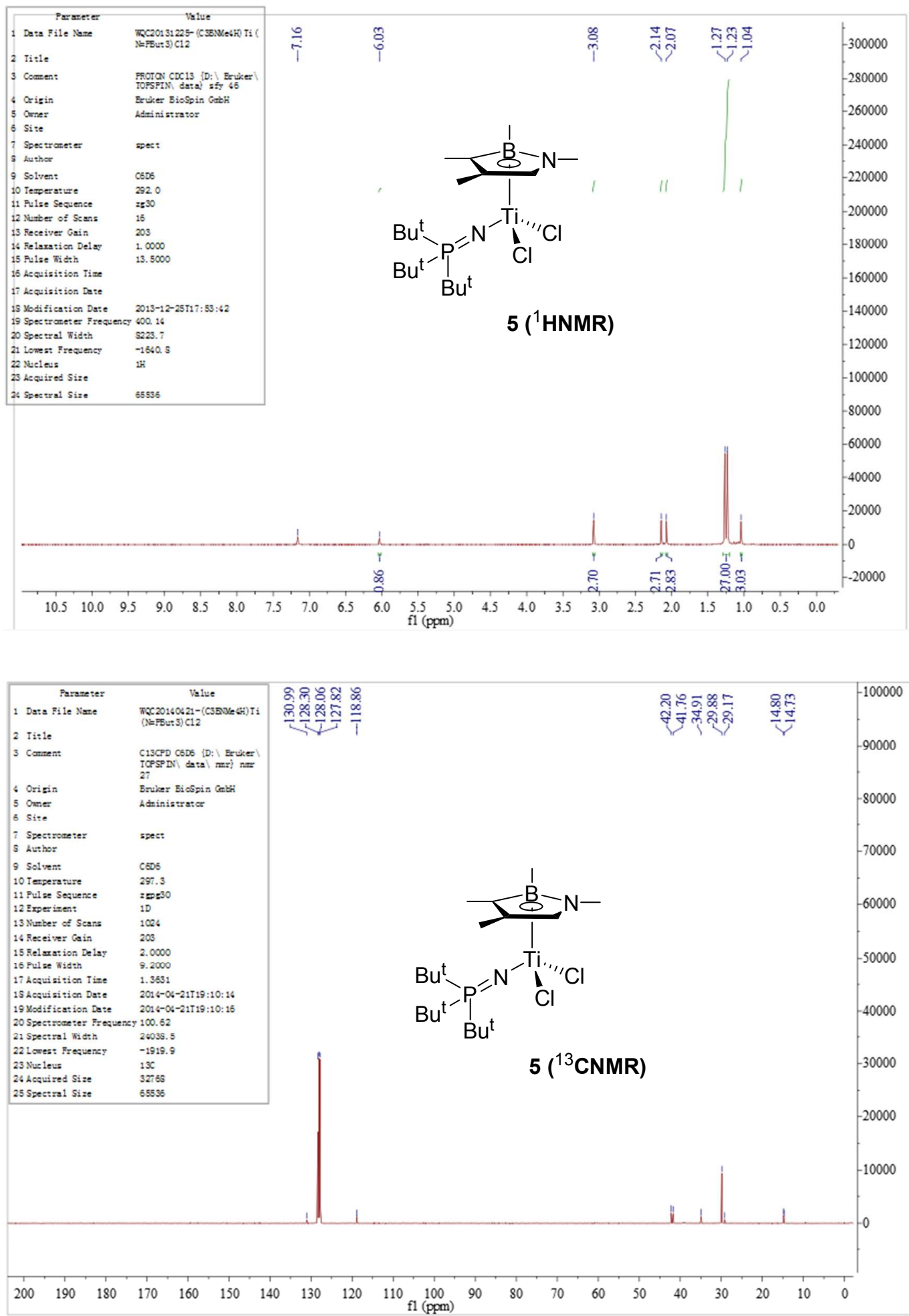

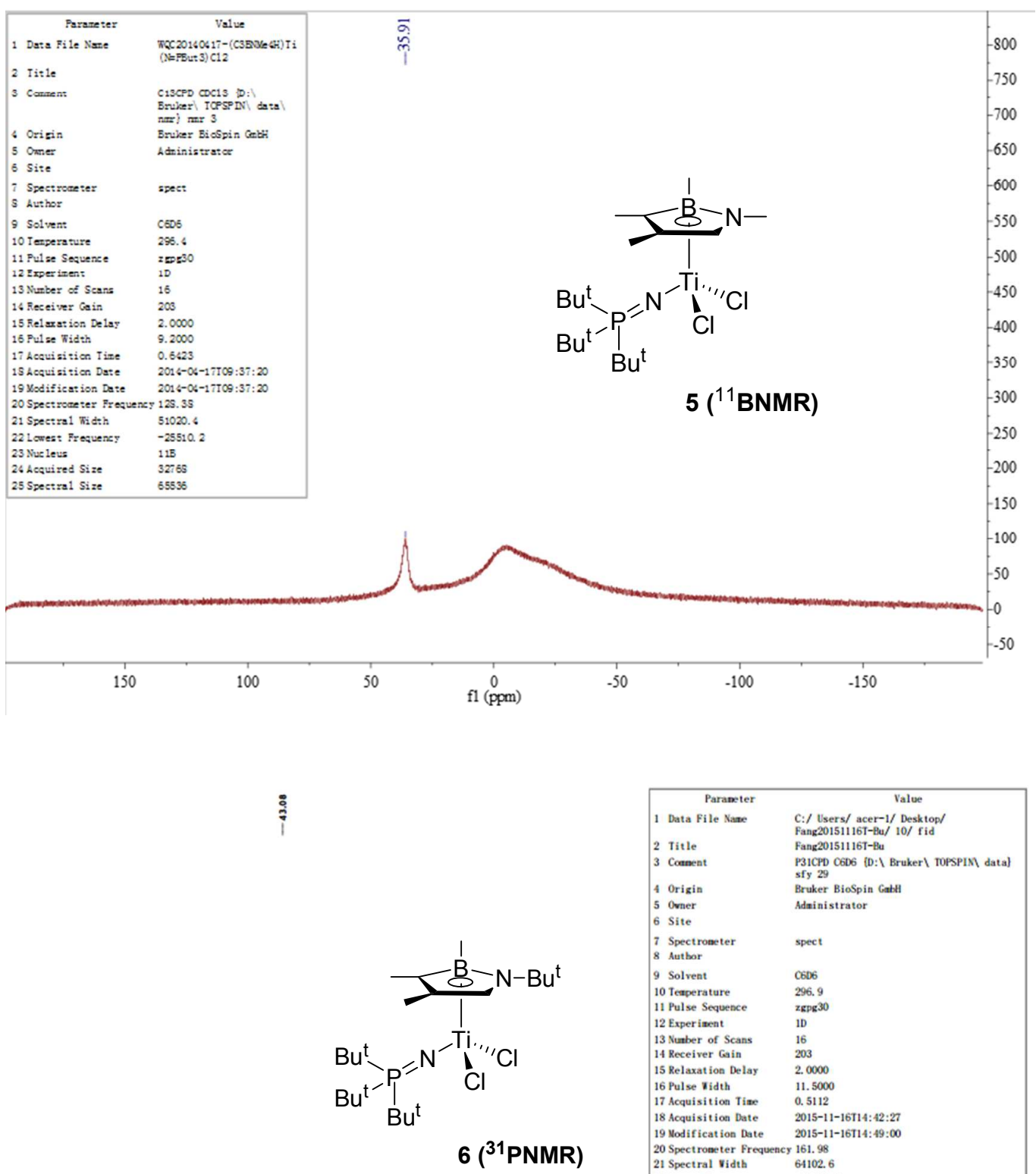

\begin{tabular}{|c|c|}
\hline Parameter & Value \\
\hline 1 Data File Kase & $\begin{array}{l}c: \text { / Isers/ acer-1/ Desktop/ } \\
\text { Fang20151116T-fu/ } 10 / \mathrm{fid}\end{array}$ \\
\hline 2 Title & Fang20151116T-8u \\
\hline 3 Coment & $\begin{array}{l}\text { P31CPD C6D6 [D: } \\
\text { sfy } 29\end{array}$ \\
\hline 4 Origin & Bruker Biospin Gabth \\
\hline 5 Ovner & Adainistrator \\
\hline 6 Site & \\
\hline $\begin{array}{l}7 \text { Spectroneter } \\
8 \text { Autbor }\end{array}$ & spect \\
\hline 9 Solvent & 0606 \\
\hline 10 Tesperature & 296.9 \\
\hline 11 Pulse Sequence & zgpe 30 \\
\hline 12 Exper isent & 1D \\
\hline 13 Number of Scans & 16 \\
\hline 14 Receiver Gain & 203 \\
\hline 15 Relaxation Delay & 2. 0000 \\
\hline 16 Pulse Vidth & 11.5000 \\
\hline 17 Acquisition Time & 0.5112 \\
\hline 18 Acquisition Date & $2015-11-16 \pi 14: 42: 27$ \\
\hline 19 Vodification Date & 2015-11-16T14:49:00 \\
\hline 20 Spectroneter Frequeney & 161.98 \\
\hline 21 Spectral Vidth & 64102.6 \\
\hline 22 Lonest Frequency & -40150.2 \\
\hline 23 Nucleus & $31 \mathrm{P}$ \\
\hline 24 Acquired Size & 32768 \\
\hline 25 Spectral Size & 65536 \\
\hline
\end{tabular}




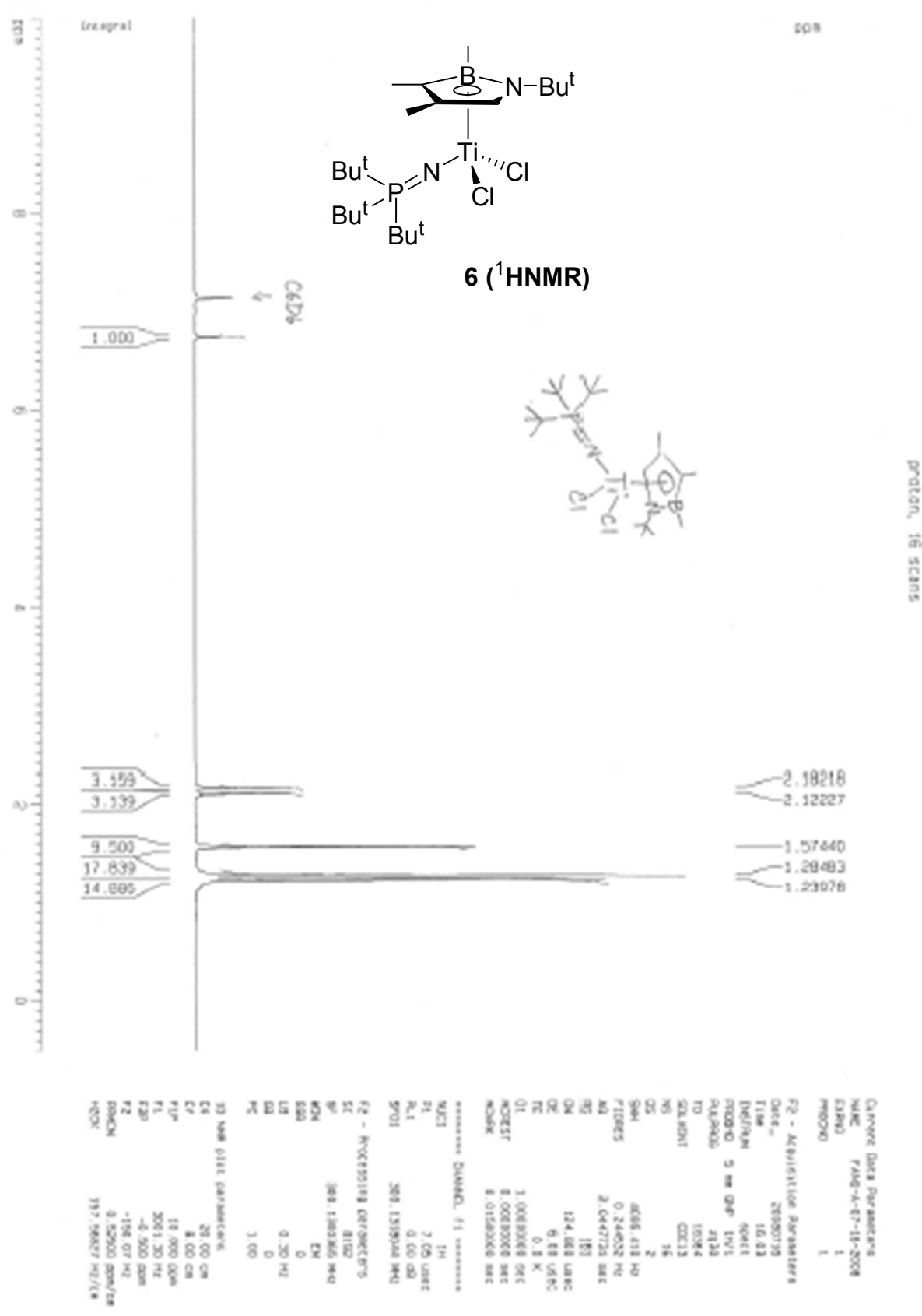




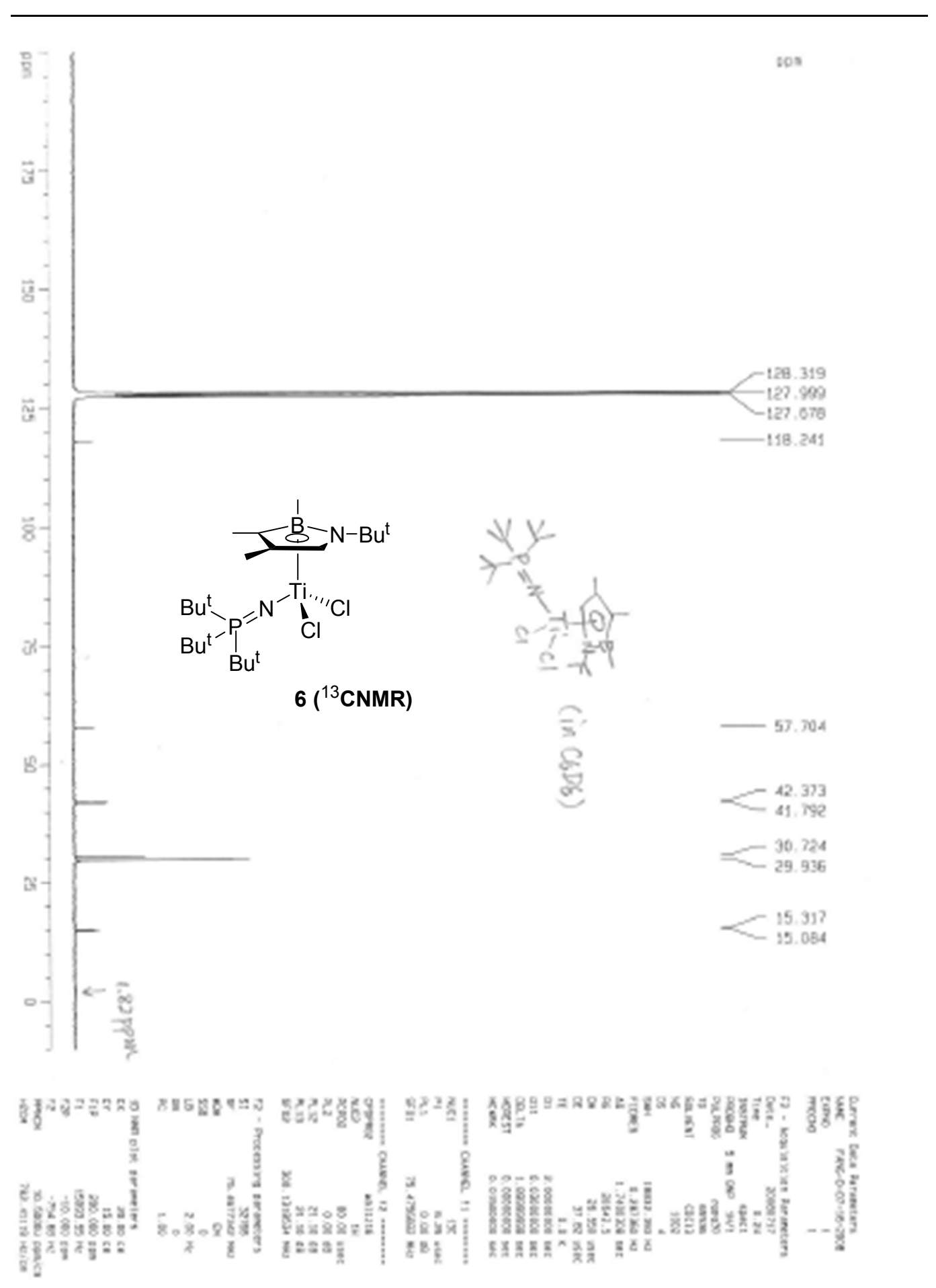



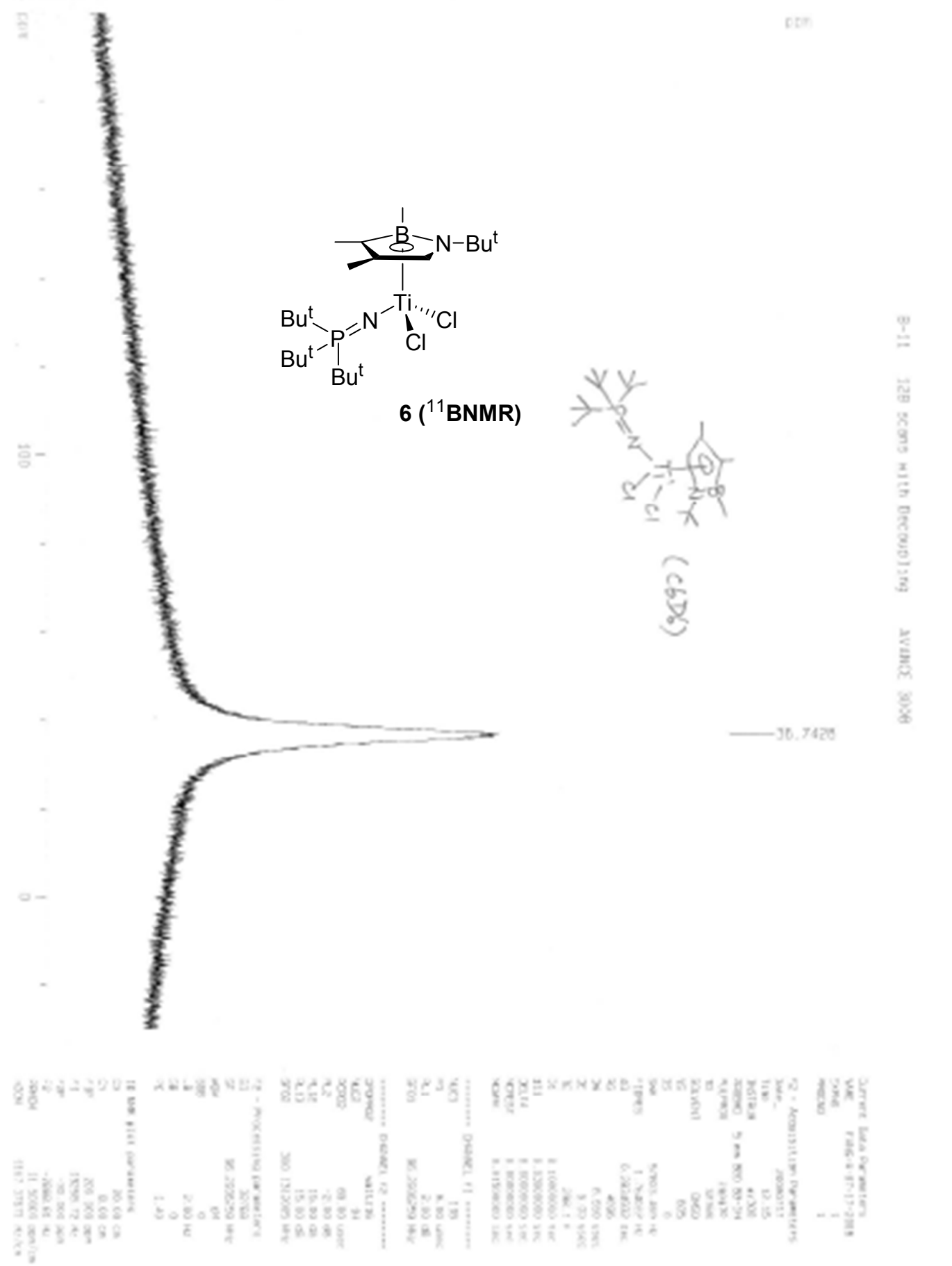

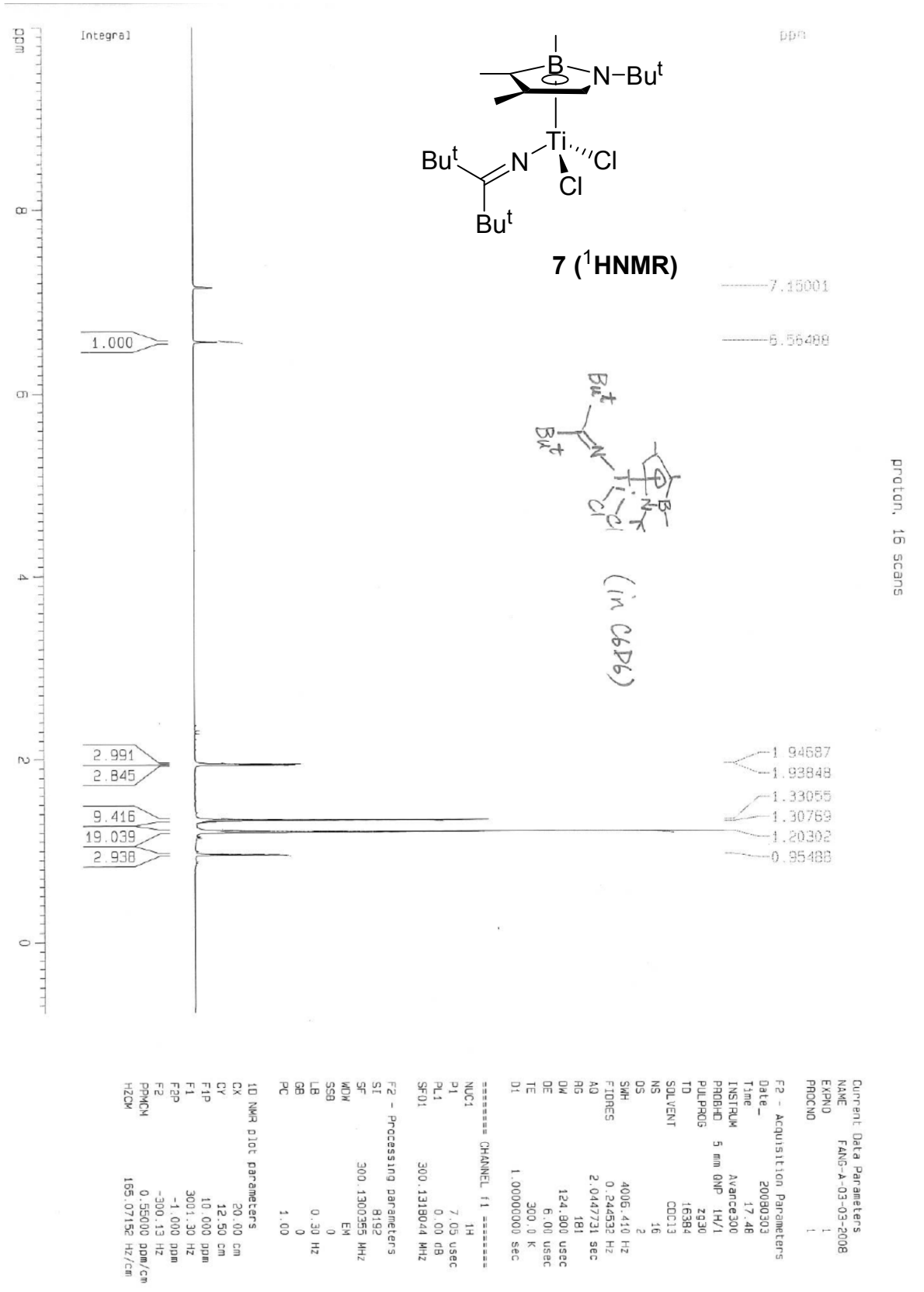

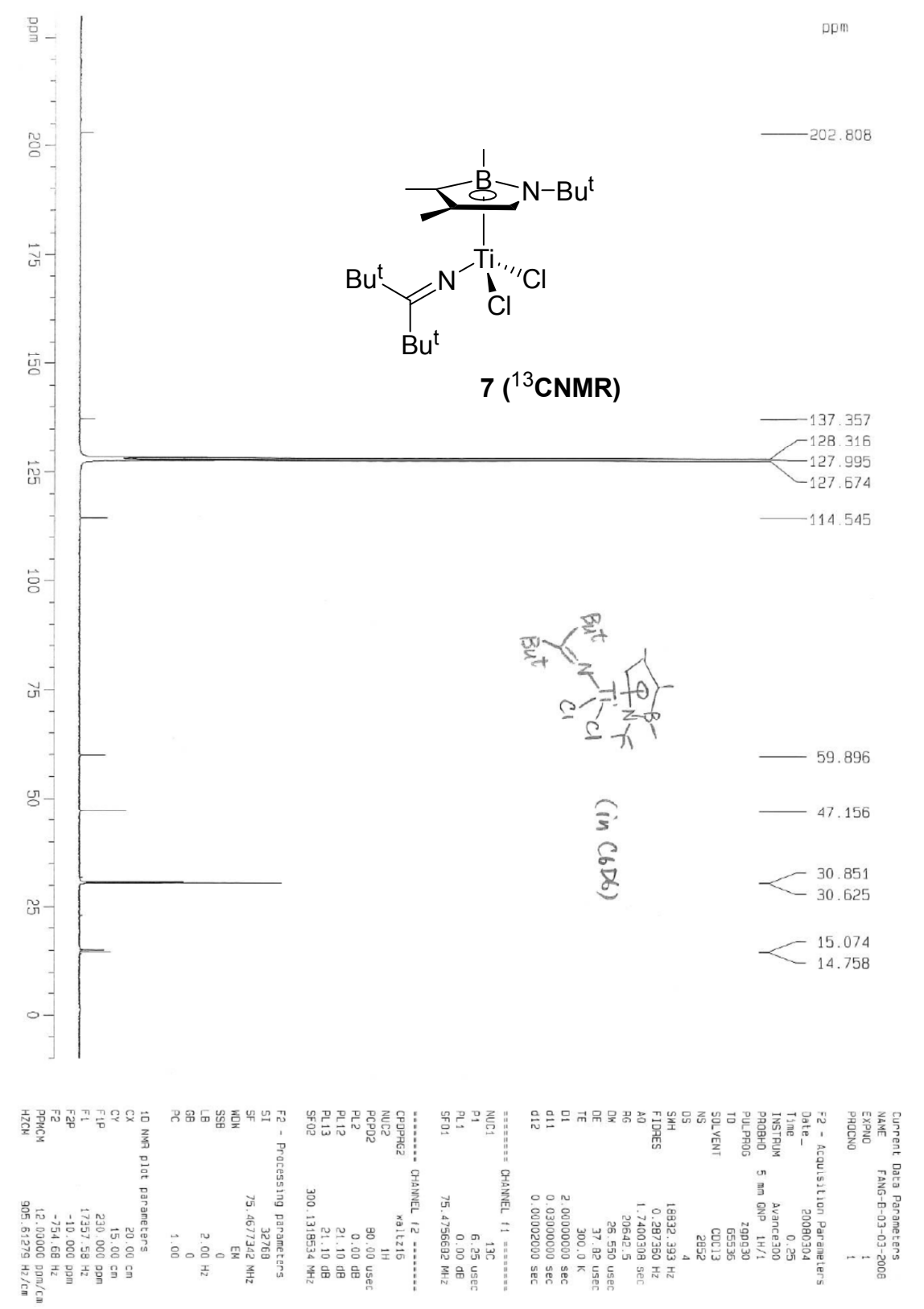


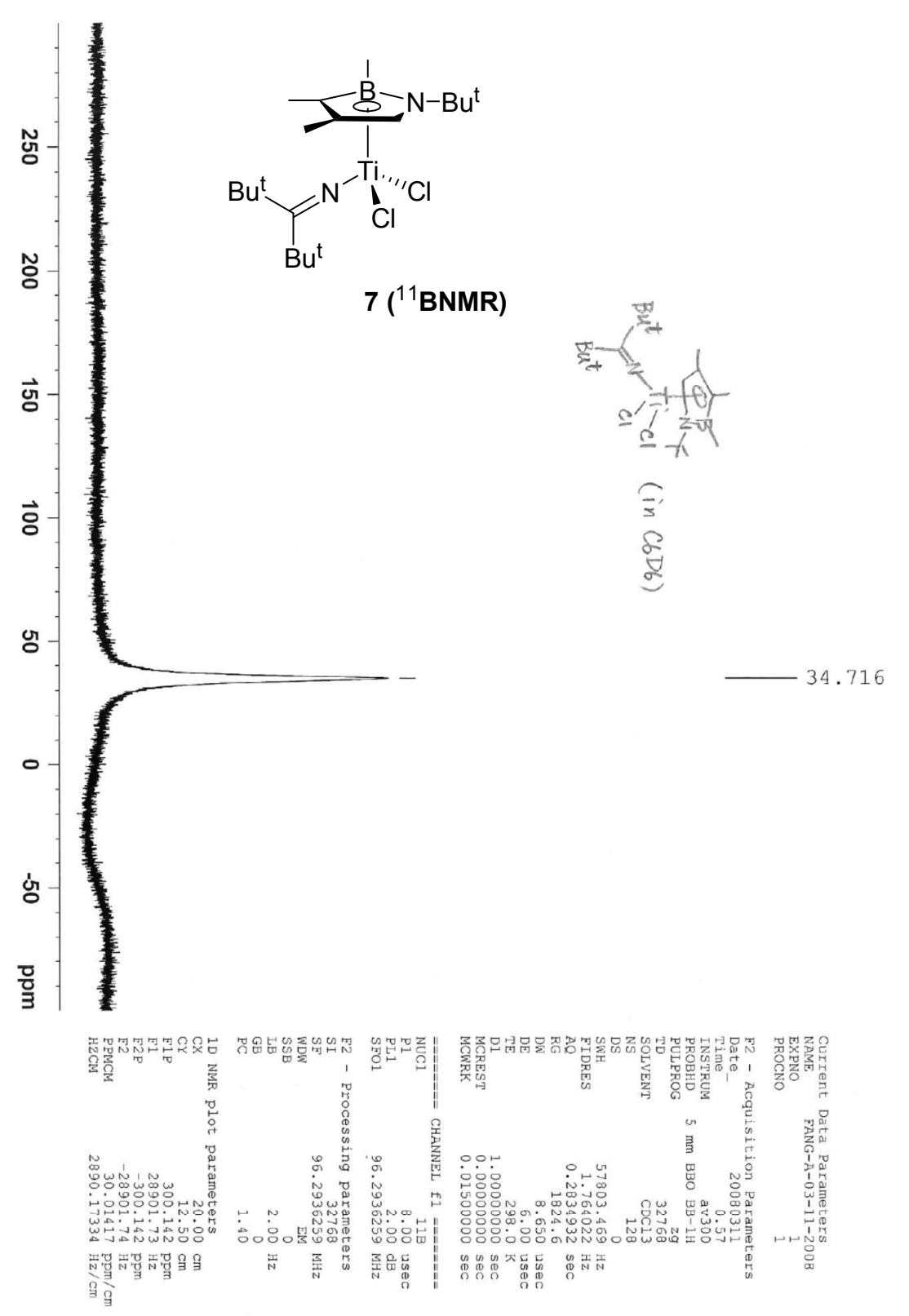




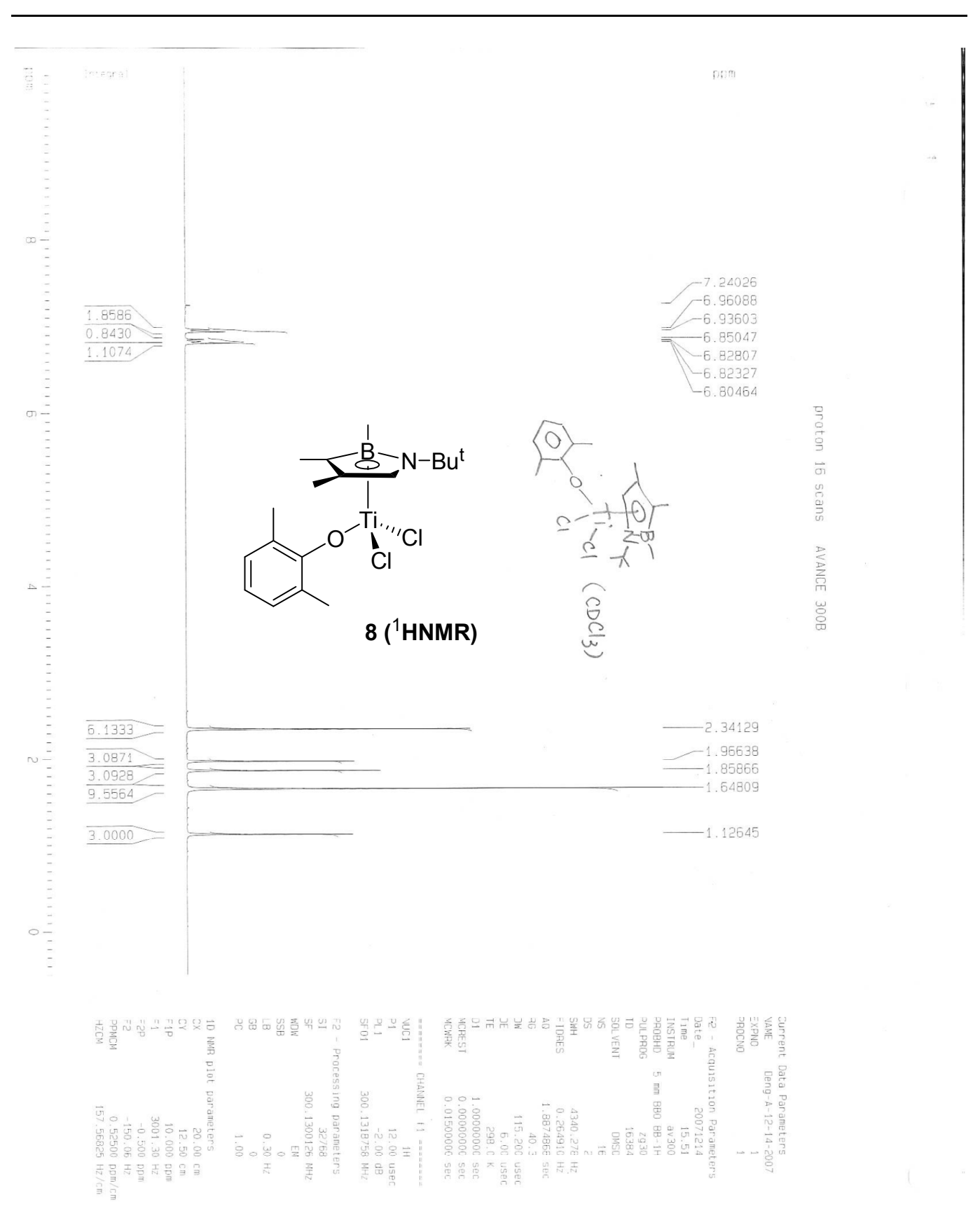




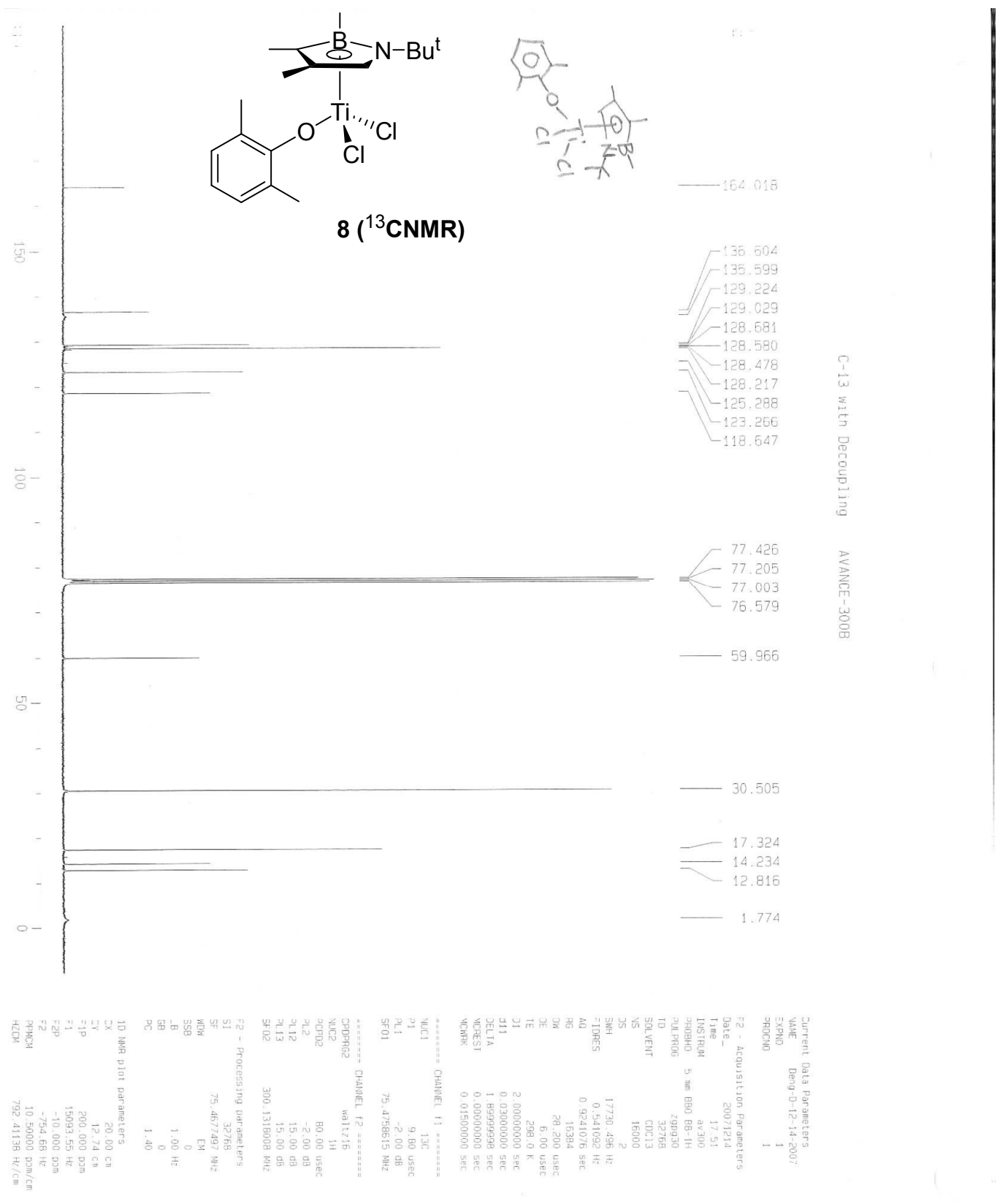




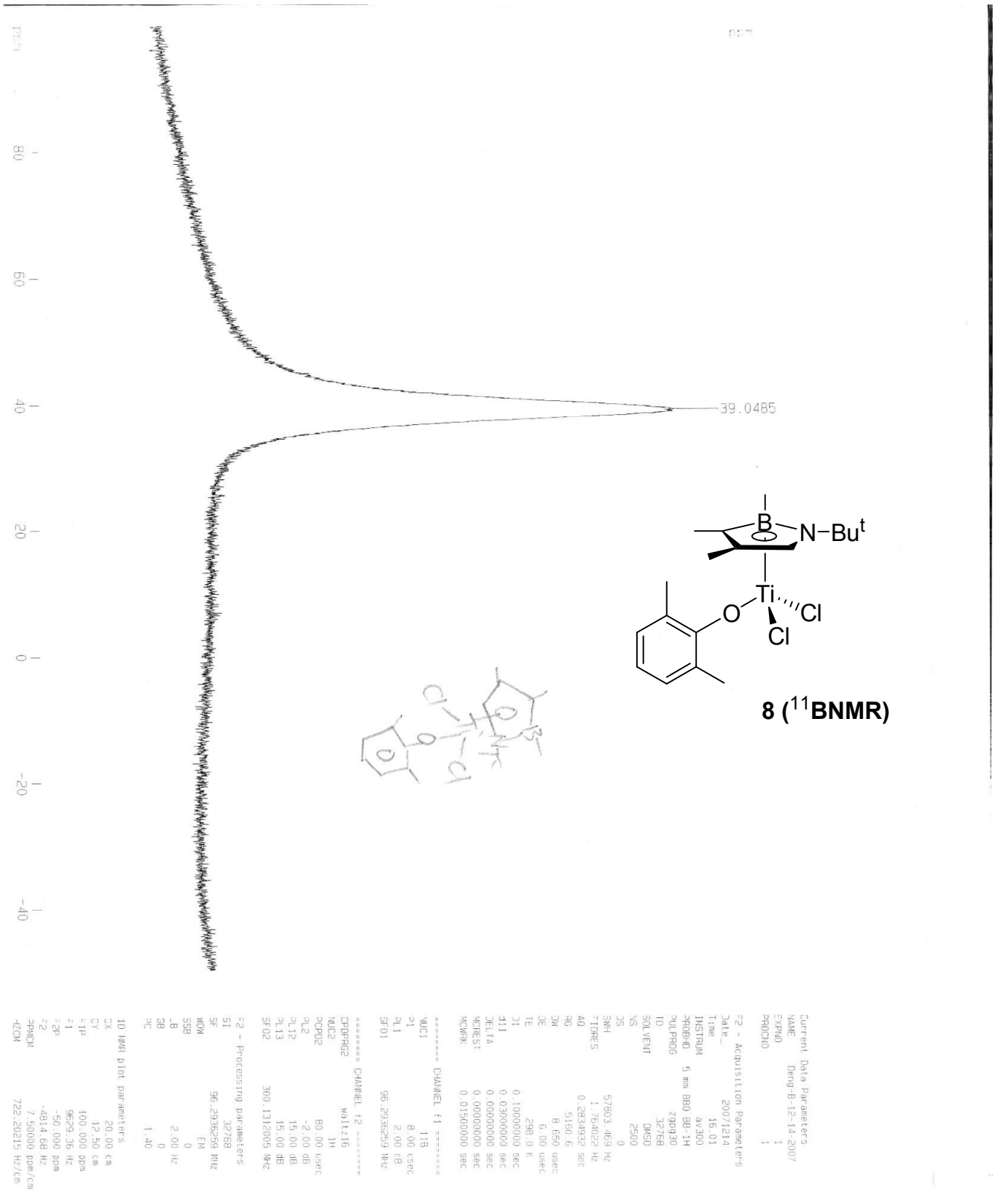

